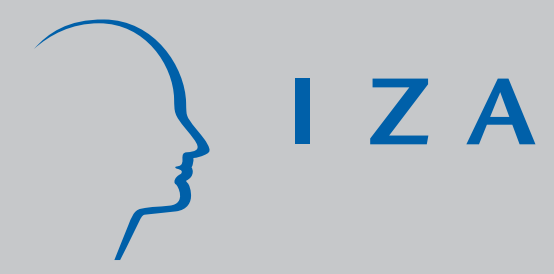

IZA DP No. 1803

Medical Interventions among Pregnant Women in Fee-for-Service and Managed Care Insurance: A Propensity Score Analysis

Leo Turcotte

J ohn Robst

Solomon Polachek

October 2005 


\title{
Medical Interventions among Pregnant Women in Fee-for-Service and Managed Care Insurance: A Propensity Score Analysis
}

\author{
Leo Turcotte \\ West Chester University \\ John Robst \\ University of South Florida \\ Solomon Polachek \\ State University of New York at Binghamton \\ and IZA Bonn
}

Discussion Paper No. 1803

October 2005

\author{
IZA \\ P.O. Box 7240 \\ 53072 Bonn \\ Germany
}

Phone: +49-228-3894-0

Fax: +49-228-3894-180

Email: iza@iza.org

Any opinions expressed here are those of the author(s) and not those of the institute. Research disseminated by IZA may include views on policy, but the institute itself takes no institutional policy positions.

The Institute for the Study of Labor (IZA) in Bonn is a local and virtual international research center and a place of communication between science, politics and business. IZA is an independent nonprofit company supported by Deutsche Post World Net. The center is associated with the University of Bonn and offers a stimulating research environment through its research networks, research support, and visitors and doctoral programs. IZA engages in (i) original and internationally competitive research in all fields of labor economics, (ii) development of policy concepts, and (iii) dissemination of research results and concepts to the interested public.

IZA Discussion Papers often represent preliminary work and are circulated to encourage discussion. Citation of such a paper should account for its provisional character. A revised version may be available directly from the author. 
IZA Discussion Paper No. 1803

October 2005

\title{
ABSTRACT \\ Medical Interventions among Pregnant Women in Fee-for-Service and Managed Care Insurance: A Propensity Score Analysis
}

\begin{abstract}
We extend prior research on the effect of managed care on the receipt of four medical interventions for pregnant women: ultrasound, induction/stimulation of birth, electronic fetal monitor, and cesarean delivery. Propensity score methods are used to account for sample selection issues regarding insurance choice. Managed care enrollees are more likely to receive an ultrasound, which may be indicative of receiving better prenatal care. Managed care plans reduce the rate of cesarean deliveries, but such limitations may be beneficial given the substantial medical evidence that cesarean deliveries are over utilized. The results indicate that insurance coverage does influence treatment intensity, but that utilization controls and provider financial incentives do not adversely affect care for pregnant women.
\end{abstract}

JEL Classification: $\quad$ I10

Keywords: health insurance, managed care, procedure utilization

Corresponding author:

Solomon W. Polachek

Department of Economics

State University of New York at Binghamton

Binghamton, New York 13902

USA

Email: polachek@binghamton.edu 


\section{Introduction}

Health care spending and the corresponding cost of health insurance have been increasing faster than gross domestic product for many years. As a result firms have taken steps to reduce or at least minimize the growth in the cost of health insurance benefits. Similarly, states and the federal government have attempted to slow the growth in public programs such as Medicaid. Some firms have passed the higher cost on to employees in the form of higher employee contributions toward premiums (Gruber and McKnight, 2003). Others have offered employees the option of enrolling in a health maintenance organization (HMO), while several states require Medicaid enrollees to join HMOs. Such efforts lead to a rapid growth in managed care enrollment during the 1980s and 1990s.

Managed care has evolved over time into many different forms. Some health maintenance organizations own their own hospitals and/or employ their own physicians. Others pay physician groups capitated amounts to care for enrollees in the HMO. The physician group receives a set amount of money per plan enrollee and assumes the financial risk of caring for patients. HMOs may also form networks of participating providers with whom the HMO negotiates fee-for-service payment rates.

Managed care has proven successful at lowering the cost of treatment. Cutler, McClellan, and Newhouse (2000) found that cost reductions in the treatment of heart disease are achieved, not through a reduction in care or outcomes, but through negotiating lower prices with health care providers. Cost reductions can also be achieved by restricting patient access to more expensive treatment options. Compared to fee-for-service insurance, HMOs provide care in different settings and with different types of providers. Managed care enrollees are more likely to be treated in outpatient settings (Manning, Leibowitz, Goldberg et al., (1984), be treated by 
generalist physicians than specialists (Flood, Fremont, Jin et al., 1998), receive fewer diagnostic tests (Chernew, 1995), and have lower rates of utilization of expensive technologies (Miller and Luft, 1994). Treatment patterns are guided by HMOs by requiring prior approval before inpatient stays or specialists are consulted. HMOs can also deny coverage for specific tests and procedures (Schifrin, Jacobs, Romans, Cruess, and Kelly, 2001).

The purpose of this paper is to compare the treatment of managed care and fee-forservice enrollees during pregnancy and birth. Opportunity exists for insurance type to affect prenatal care by influencing the type of provider (family physician versus obstetrician) and diagnostic tests performed. While treatment setting during birth is unlikely to vary since most births take place in a hospital, treatment intensity may differ with insurance type. With the exception of cesarean deliveries, the relationship between insurance type and the receipt of specific procedures has received little attention in the literature. ${ }^{1}$ This paper examines the utilization of four medical interventions for pregnant women: ultrasound, induction/stimulation of birth, electronic fetal monitor, and cesarean delivery.

In addition, this study differentiates between women with and without medical risks and complications. Most studies control for the presence of medical risks and complications but do not consider whether utilization differences between insurances depend on such factors. Given such pregnancies require greater treatment intensity policy makers should be particularly concerned if HMOs restrict care for women with risks and complications. Alternatively, it may not be problematic and may even be welfare enhancing if HMOs restrict access to cesarean deliveries for women without risks or complications.

Examining the effects of insurance coverage is complicated because insurance choices are based on expected utilization. Women who expect to need more care may enroll in insurance 
types that provide better benefits and/or less restrictive treatment protocols (Robinson, Gardner, and Luft, 1993). Two approaches are used simultaneously to account for potential selection issues. First, propensity scores are estimated to adjust for group differences across insurance types. ${ }^{2}$ Propensity scores adjust for pre-treatment differences across groups that are correlated with both the decision to select an insurance type and the expectation of using services. Second, examining relatively homogeneous subgroups should limit selection problems. For example, Cutler, McClellan, and Newhouse (2000) examined treatment and outcomes for the treatment of heart attack. While patients may select an insurance plan based on the expectation of developing heart disease or for that matter the expectation of developing any serious disease, the authors argue that once the attack occurs, the individual is locked into their plan, at least for the duration of the enrollment period. As such, selection effects are minimized when limiting the sample to people who recently developed a disease. This paper takes a similar approach by examining women with medical risks who develop complications during pregnancy as a distinct subgroup. Women may choose an insurance plan based on the expectation of developing complications, but once the complication exists they are locked into their insurance plan for the duration of the pregnancy.

We begin in Section 2 with a discussion of relevant literature. Section 3 discusses data and methodology. Section 4 provides an overview of the procedures analyzed and their expected relationship to insurance type. Section 5 presents results, while Section 6 concludes the paper.

\section{Literature}

The literature on medical interventions across insurance types takes several different approaches. Some compare private fee-for-service and managed care while others focus on the 
Medicaid program. Most focus on specific states or even specific counties to consider whether managed care enrollees receive the same care and have the same outcomes as fee-for-service enrollees.

Many look at prenatal care, as measured by the number of physician visits during pregnancy, cesarean deliveries, and outcomes such as birth weight and mortality. Two studies found different results when comparing prenatal care and birth outcomes for fee-for-service and HMO enrollees in the Northwest. Quick, Greenlick, and Roghmann (1981) found that women enrolled in HMOs in the Portland, Oregon area begin prenatal care later than those with fee-forservice insurance. Controlling for maternal risk, HMO enrollment is associated with greater birth weight, but no significant difference exists in mortality. Aitken, Warden, and Critchlow (1997) found that women in King County Washington covered by managed care are more likely to receive ultrasounds, adequate prenatal care, and babies are less likely to be below 2500 grams. There is no difference in cesarean section rates. Despite such results, HMO covered women with medical risk factors have a higher likelihood of labor and delivery complications.

While there is no significant difference in c-section rates between HMOs and fee-forservice in Washington, other studies have found that HMO enrollees are less likely to receive cesarean deliveries. ${ }^{3}$ For example, Tussing and Wojtowycz (1994) found HMO enrollees in New York State have a lower incidence of cesarean deliveries, but the effect is rather small, in the 1-3 percent range. Similarly, Stafford (1990) found that women with private insurance in California are more likely than HMO enrollees to receive a cesarean delivery. Keeler and Brodie (1993) suggest that economic incentives may play a role in cesarean deliveries. Women with private fee-for-service insurance have the greatest likelihood of cesarean deliveries due to a combination of the higher provider reimbursements and the low financial cost to women. 
Comparing utilization and outcomes among insurance types assumes that the effects are due to insurance and not the types of providers that participate with specific insurances. For example, providers that tend to perform fewer procedures may be more likely to participate in managed care provider networks. If so, the effect of provider practice patterns may be incorrectly attributed to insurance. Wright, Gardin, and Wright (1984) examined fee-for-service and managed care outcomes within a physician practice. By looking at a single physician practice this study was able to control for practice patterns of physicians. Women with managed care coverage have less prenatal care measured by number of visits, no difference in prenatal complications, shorter lengths of stay, and fewer cesarean deliveries. Alternatively, Wilner, Schoenbaum, Monson, Winickoff (1981) focus on a single hospital by comparing fee-for-service and managed care enrollees at Brigham and Women’s Hospital. The authors found fee-forservice enrollees are more likely to receive cesarean deliveries and have longer lengths of stay. The difference in average hospital stay is due entirely to the lower incidence of cesarean deliveries among HMO enrollees. HMO enrollees also have more prenatal care and lower rates of induced deliveries. Outcomes such as stillbirths, neonatal death, Apgar scores, and low birth weights are similar for fee-for-service and managed care enrollees. Overall, Wilner et al. (1981) concluded that the quality of care and outcomes does not vary significantly between managed care and fee-for-service payment sources.

Research has also compared Medicaid fee-for-service with Medicaid managed care. ${ }^{4}$ These studies examined Medicaid enrollees in specific states that have fee-for-service and capitated components to their Medicaid programs. Koroukian, Bush, and Rimm (2001) found that patients in the Ohio Medicaid program with managed care coverage are less likely to receive a cesarean section but that the difference narrowed between 1992 and 1997. Other studies show 
no difference between capitated and fee-for-service Medicaid programs. Weinstein and Trussell (1998) examined cesarean delivery rates in California between 1983 and 1994. Similarly, Oleske et al. (1998) examined 1993 California data for women enrolled in the Medi-Cal program (the California Medicaid program). The method of provider reimbursement varies across counties with fee-for-service payments in some counties and capitated payments in others. Carey, Weis, and Homer (1991) compared capitated and fee-for-service Medicaid programs in California and Missouri. Krieger, Connell and LoGerfo (1992) compared the use of prenatal care and outcomes among managed care and fee-for-service enrollees in the state of Washington. The method of reimbursement in Medicaid programs did not impact cesarean section rates, prenatal care, or infant outcomes.

\section{The Data and Methodology}

This analysis uses data provided by the New York State Department of Health. The data are from two sources: the NYS Vital Statistics (VS) matched infant birth-death file and the Statewide Planning and Research Cooperative System (SPARCS) file for 1993-1996 inclusive. Each birth in the SPARCS file is matched to its corresponding VS record. ${ }^{5}$ The SPARCS data contain inpatient information including the type of primary payer: Blue Cross Blue Shield (BCBS), self-administered plan, self-pay, commercial insurer, three public insurers (Medicaid, Medicare, Civilian Health and Medical Plan for the Uniformed Services), and three managed care plans (Medicaid, HMO Blue and commercial HMO). ${ }^{6}$ Included in the VS data are certain obstetrical procedures, a wide range of maternal medical risks, complications during labor or delivery, and non-medical risks (e.g., smoking, tobacco use), ${ }^{7}$ and women’s demographic 
characteristics. Our analysis is conducted for all births to women 15-44 years of age that take place in a hospital.

We focus the comparisons on fee-for-service BCBS and HMO Blue, and commercial feefor-service and HMOs. ${ }^{8}$ We do not examine differences between Medicaid fee-for-service and managed care since the number of births covered by a Medicaid HMO was too small to make reliable comparisons. BCBS is considered separately from other private insurers since it has long held a unique niche in the health care sector. For example, Blair, Ginsburg, and Vogel (1975) argued that BCBS plans have received favorable regulatory treatment over time and that BCBS has used its market power to keep provider payments and consumer premiums low (Foreman, Wilson, and Scheffler, 1996). New York State (excluding New York City) is represented by several different BCBS fee-for-service insurers including BCBS of Western New York, Empire BCBS, BCBS of Central New York, BCBS of Utica-Watertown, The Finger Lakes Companies, and Blue Cross of Northeastern New York. Each insurer also offers a managed care product.

The first step in the analysis is to compute propensity scores. Propensity scores have been used for many years to account for non-random differences between groups of people (Rosenbaum and Rubin, 1983). Imbens (2000) extended the methodology to cases where there are more than two treatment groups by building on the fact the propensity score matching is basically a weighting mechanism. The weights are computed by taking the inverse of the predicted probability that an individual chooses the insurance type that she actually selects. ${ }^{9}$ The probability is computed from a multinomial logit model where the insurance choices are a function of observed characteristics:

$$
\text { INSURANCE_TYPE } E_{i}=X_{i} \cdot \beta+Z_{i} \cdot \alpha+u_{i}
$$


where INSURANCE_TYPE represents the ten insurance options (BCBS, self-administered plan, commercial insurer, Medicaid, Medicare, CHAMPUS, self-pay (i.e., uninsured), and three managed care plans (Medicaid, HMO Blue and commercial HMO); $X$ is a vector of the individual's demographic characteristics: age is a continuous variable for all women of child bearing age (15-44), race is separated into three categories (white, black, other), education denotes the number of years of schooling completed, marital status and Hispanic are categorical variables, degree of urbanization is a vector of categorical variables denoting the Rural-Urban Continuum Codes for Metropolitan and Non-metropolitan Counties. It is necessary to control for urbanization since HMOs are typically in urban areas. The specification also includes a vector (Z) of medical risks and non-medical risks (e.g., smoking, tobacco use). For those without medical risks this vector reduces to non-medical risks only.

Next, analysis of the effects of health insurance consists of estimating separate regressions for each procedure. Optimally, we would compare procedure utilization for individuals with multiple births covered by different insurance types. However, since the data are not designed to be longitudinal, we rely on cross sectional variation to examine how insurance coverage affects the likelihood of receiving each procedure. The four years of data are pooled to provide sufficient sample sizes for each subgroup of women. All procedure regressions are weighted by the propensity score discussed above to account for sample selection bias. Logit models are estimated as follows:

$$
\text { PRENATAL_ULTRASOUND }{ }_{i}=X_{i} \cdot \beta+I N S U R A N C E \_T Y P E_{i} \cdot \delta+Z_{i} \cdot \alpha+u_{i}
$$

where PRENATAL_ULTRASOUND is a dichotomous variable indicating whether individual $i$ received an ultrasound during pregnancy; $X$ is the same vector of the individual demographic characteristics described above; INSURANCE_TYPE is a vector of categorical variables denoting 
nine of the ten insurance options (commercial fee-for-service insurance is the omitted category). The specification also includes the vector $(Z)$, which now includes the complications that develop during labor or delivery as well as the medical and non-medical risks. We control for the risks and complications but cannot determine whether they are truly known at the time an ultrasound is typically received. Again, for those without medical risks or complications, this vector reduces to non-medical risks only.

We also estimate a specification to examine procedures given during delivery ${ }^{10}$ :

$$
\text { PROC }_{i}=X_{i} \cdot \beta+B I R T H_{i} \cdot \rho+\text { INSURANCE_TYPE } E_{i} \cdot \delta+Z_{i} \cdot \alpha+u_{i}
$$

where $P R O C$ is a dichotomous variable indicating whether individual $i$ received the procedure being analyzed; BIRTH contains a vector of variables characterizing the birth that may influence the need for a procedure, including dummy variables denoting the trimester in which the person began receiving prenatal care and whether a breech birth, and continuous variables measuring the length of gestation, the mother's weight and weight gain, and the baby's weight at birth.

There is a potential problem with the approach. As noted earlier, practice patterns vary across physicians and hospitals. Such patterns may be associated with physicians participating in HMO networks or the proportion of patients with HMO coverage. Whereas these problems may be relevant, almost all the studies discussed earlier suffer from the same shortcomings. Only Wright, Gardin, and Wright (1984) control for the practice patterns of physicians, but this is accomplished by limiting the sample to a single provider group. Such a restrictive sample would make it difficult to generalize the results.

\section{The Procedures and Expected Relationship to Insurance Type}


Multiple actors including physicians, patients, and insurers determine the utilization of medical procedures. A number of theoretical models predict a relationship between insurance type and physician-induced demand for services (Evans, 1974; Farley, 1986; De Jaeger and Jegers, 2000). As long as the price received by physicians exceeds their marginal cost, they may provide care in excess of what a perfectly informed patient would desire. Accordingly, in the absence of other utilization controls, payment differences across insurances may influence patient care. Relative to fee-for-service, providers participating in managed care networks face different financial considerations and thus may provide different services. Managed care organizations may offer financial incentives to primary care physicians such as bonuses or financial penalties such as withholding payments in order to limit referrals. ${ }^{11}$ HMOs also negotiate lower provider payments for services than most fee-for-service plans lowering the marginal price received by physicians. Some OB/GYN providers report being terminated from managed care networks due to not meeting the HMOs utilization guidelines (Schifrin, et al., 2001). In addition, fifty percent of surveyed providers reported having an HMO deny coverage for care they had recommended. Denials of coverage increase the out-of-pocket price of medical care for patients, and are likely to reduce the quantity demanded of medical care. Below we discuss whether HMOs have an incentive to affect procedure utilization, and in such cases how HMOs establish incentive structures to effect utilization.

\section{Ultrasound}

The first procedure, ultrasound, is typically performed 18-20 weeks into the pregnancy. Ultrasounds have become a standard part of prenatal care to detect problems early in the

pregnancy and to confirm the due date. ${ }^{12}$ Some ultrasounds are also performed during delivery, 
especially for certain complications and prior to some cesarean deliveries. As such, we consider the receipt of an ultrasound during pregnancy to be an indicator of prenatal care, and we examine ultrasounds during delivery as a separate procedure. Over 96 percent of the ultrasounds reported in our data were performed prior to labor/delivery.

There is some debate over whether women without risks or complications need to have an ultrasound performed (Seeds, 1996; Long and Sprigg, 1998). Given such debate, we expect that some women do not receive ultrasounds during pregnancy and women without risks or complications are less likely to receive the procedure than women with risks and complications. Despite the debate about the necessity for low-risk patients, we expect HMO enrollees are more likely to receive an ultrasound than fee-for-service enrollees. Long and Sprigg (1998) performed a cost-benefit analysis of whether the routine provision of ultrasounds was practical financially. Routine ultrasounds were able to detect anomalies in patients that would not been candidates for high-risk screenings. A high proportion of those pregnancies were terminated resulting in a long-term savings on treatment and care far in excess of the cost of providing the ultrasounds to all women. Thus, HMOs may provide financial incentives to patients and providers to encourage women to receive routine ultrasounds, especially low-risk patients that might not otherwise receive them.

Given that ultrasounds during delivery are often performed when there are complications we expect utilization to be higher when such complications exist. Ultrasounds are also performed during delivery when one was not performed during the pregnancy. As such, given that we expect ultrasounds to be more likely in managed care, we expect the receipt of ultrasounds at delivery to be more common with fee-for-service insurance. 


\section{Induction/Stimulation}

The remaining three procedures, induction/stimulation, fetal monitor, and cesarean section are typically provided immediately prior to or during delivery. Induction involves the starting or speeding up of labor contractions by the use of drugs or other methods. There are several reasons why labor may be induced. Some women have small pelvises, and birth is induced before the baby becomes too large to be delivered vaginally. Some pregnancies are induced because the baby is post-term, because of an illness associated with pregnancy such as toxemia, or due to a long labor. In other cases, labor is induced for convenience to deliver the baby on a specific date. Stimulation involves the augmentation of established labor typically through the use of oxytocin (Mathews, 1997). The procedure is usually used when contractions occur in an irregular pattern. Induction and stimulation may be used together or individually.

The use of induction and stimulation has been increasing rapidly. The rate of induction rose from 9.4 percent of births in 1990 to 19.4 percent in 1998 (Rayburn and Zhang, 2002), while the use of stimulation rose from 10.9 to 16.1 percent between 1989 and 1995 (Mathews, 1997). Inductions are performed for medical reasons such as a post-term pregnancy, medical condition, and fetal compromise. However, much of the growth in utilization was due to elective reasons such as patient convenience. This has led some to raise concerns over the use of a medical intervention that is not medically necessary (Rayburn and Zhang, 2002). Still, given that many inductions and stimulations are performed due to the presence of medical conditions, we expect greater utilization among women with medical risks and complications.

It is difficult to predict whether HMO enrollees are more or less likely to be induced/stimulated. Given that some inductions are for patient convenience, one might expect that HMOs would discourage the use of the procedure. ${ }^{13}$ Post-term pregnancies however 
increase the odds of expensive adverse outcomes that HMOs desire to avoid. The existing evidence suggests that HMO enrollees are less likely to be induced (Wilner et al., 1981), but their study predates the rapid increase in the use of the procedures. As such it is important to determine whether the increase has been largely a fee-for-service phenomenon or has taken place across insurance types.

\section{Fetal Monitor}

A fetal monitor (EFM) records the women's contractions and the baby’s heartbeat. Fetal monitors can be either external, such as a microphone placed near the woman's abdomen or internal where electrodes are placed in the baby’s scalp. Fetal monitors are used during the vast majority of deliveries, although it can be used earlier in the pregnancy. In 1996, 83 percent of women were monitored electronically (Haggerty, 1999). EFM is useful for detecting early fetal distress and monitoring high-risk women during delivery (Sweha, Hacker, and Nuovo, 1999). There are risks however, including the possibility of producing false-positive results that result in unnecessary surgical procedures. As such, fetal monitor usage is more likely when the woman has maternal risks and complications. Similar to the provision of ultrasounds, we expect highrisk HMO enrollees are more likely to receive fetal monitors than similar fee-for-service enrollees. EFM is a relatively inexpensive procedure (approximately $\$ 150$ per case) that by alerting providers early may reduce high cost complications and perinatal mortality. ${ }^{14}$

\section{Cesarean Delivery}

Cesarean deliveries involve a surgical procedure to deliver the baby. Cesareans may be performed for medical reasons such as if the woman is ill, the pelvis is too small for natural 
childbirth, the baby is in a breach position, or active labor has been ongoing for a long time. Other times, cesareans are performed in order to schedule the delivery of the baby. The majority of cesarean sections are due to four complications: breech, dystocia (slow to progress labor), fetal distress, and previous cesarean section. Cesareans may be performed after induction or without induction. The rapid rise in cesarean deliveries has been accompanied by an increase in the dystocia and fetal distress diagnoses. Given that these diagnoses are somewhat subjective, several have suggested that physicians are using these diagnoses somewhat liberally (Tussing and Wojtowycz, 1994).

In the absence of constraints or other incentives, physicians may provide more cesarean deliveries than optimal. The fee for a cesarean section is typically greater than for a vaginal delivery, and the time required to perform a c-section is typically less than for a normal delivery. Indeed, many argue such financial and time incentives have contributed to the tremendous growth in cesarean deliveries over the past few decades. Gruber and Owings (1996) find cesarean delivery increased 240 percent from 1970 to 1982 . They claim that physicians overused cesarean delivery relative to what would be chosen by a financially disinterested provider. In addition, Keeler and Brodie (1993) argue that women also have economic incentives to demand too many cesarean deliveries.

As such, HMO enrollees are expected to receive fewer cesarean deliveries than fee-forservice plans. Some HMOs, referred to as staff model HMOs, employ their own physicians and can directly influence the treatment they provide. As noted earlier, HMOs often provide financial incentives for other physicians to limit non-essential services. We expect that HMO utilization guidelines will limit cesarean deliveries, especially among women without risks or complications. 


\section{Results}

Propensity scores

Multinomial logit regressions are used to generate the probability of selecting the insurance actually chosen by each woman. The results are generally consistent with expectations. HMO enrollees are more likely to be younger, single, black, and live in metropolitan areas. Among the medical risk factors, the presence of risk factors associated with a prior or the current pregnancy reduces the likelihood of selecting HMO coverage among commercial insurance enrollees. For example, having a previous low birth weight infant, a previous birth over 4000 grams, a previous spontaneous fetal death, in vitro fertilization, or other fertilization treatment all lead individuals to choose fee-for-service commercial coverage over commercial HMO coverage. The picture is less clear for BCBS enrollees. Having a previous low birth weight infant, a previous spontaneous fetal death, or in vitro fertilization are positively related to choosing fee-for-service BCBS coverage over HMO Blue, while having a previous birth over 4000 grams, or other fertilization treatment all led individuals to choose HMO Blue coverage. Interestingly, many medical conditions (e.g., genetic diseases, heart disease, hemoglobinopathy) are positively related to selecting HMO Blue coverage, but negatively associated with choosing commercial HMO coverage. For each individual, the predicted probability of selecting the insurance type actually chosen in computed. The inverse of the probability is used to weight the regression analyses discussed below. 
Women with medical risks and complications

Table 1 reports procedure utilization for women with medical risks and complications. This group should be most likely to receive medical care. As such, differences in procedure utilization between managed care and fee-for-service insurances might be viewed as particularly troublesome. Several insurance types have very few participants. CHAMPUS, self-administered plans, Medicare, and Medicaid HMO’s each comprise less than one percent of the total sample. Also, we do not focus on the uninsured or Medicaid fee-for-service enrollees given the lack of an HMO comparison group for this analysis. As such, while we include categorical variables denoting each insurance type in the regressions, the descriptive statistics combine many of the insurance types into an “Other” category.

$<$ Table $1>$

Several points are noteworthy. Overall about 20 percent of all births involve both medical risks and complications. Thirty-six percent of high risk births are covered by either BCBS or commercial fee-for-service insurance, while 29 percent were covered by HMOs. Of the births covered by managed care, commercial insurers cover the vast majority (72 percent). Enrollees in HMO Blue have a disproportionate share of risks and complications. Thirty-seven percent of enrollees in HMO Blue have both risks and complications compared to 17-20 percent for the other three insurance types. Despite the high proportion of enrollees having high risk births, HMO Blue enrollees only account for eight percent of all high-risk births.

There are significant differences in mean procedure utilization among insurances. Pairwise t-tests are performed comparing BCBS and HMO Blue, and commercial fee-for-service and HMO coverage. Utilization is significantly different for BCBS plans, with fee-for-service 
enrollees getting more fetal monitors, and cesarean deliveries. HMO enrollees receive more ultrasounds (both during the pregnancy and during delivery), and are induced more often. Differences are less prevalent among commercial plans. HMO enrollees are more likely to have an ultrasound during delivery, while fee-for-service enrollees receive more inducements and cesarean deliveries.

Logistic regression results are reported in Table 2 to compare enrollees in managed care and fee-for-service plans. HMO Blue enrollees are 22 percent more likely than fee-for-service BCBS enrollees to receive an ultrasound during pregnancy. ${ }^{15}$ In addition, HMO Blue enrollees are 21.5 percent more likely to receive an induction/stimulation. Fee-for-service BCBS enrollees are 1.7 percent more likely to receive ultrasounds during pregnancy, 3.2 percent more likely to use a fetal monitor, and 15.5 percent more likely to receive a cesarean delivery.

Commercial insurers cover far more managed care enrollees than the non-profit BCBS plans. Comparing commercial fee-for-service and managed care enrollees provides a mixed picture. Managed care enrollees are more likely to receive an ultrasound during pregnancy and a fetal monitor during delivery, while fee-for-service enrollees are more likely to have an ultrasound during delivery and be induced/stimulated. No significant difference exists for ultrasounds during delivery or cesarean deliveries.

$<$ Table 2>

Overall, among women with medical risks and complications, managed care enrollees are more likely to receive an ultrasound than enrollees in fee-for-service plans, which is consistent with the expectation that HMO enrollees receive better prenatal care. The marginal effect for commercial insurance may seem small (.028), but given the vast majority of women receive ultrasounds, a 2.8 percent difference may be seen as an important differential. The same could 
be said for use of fetal monitors among the commercially insured. HMO Blue enrollees are less likely to receive a cesarean delivery, but it is not clear that receiving a procedure is necessarily better than not receiving the procedure. As such, the utilization effects on cesareans from managed care may be welfare improving (Lindrooth, Norton, and Dickey, 2002). In addition, the lower rate of induction for commercial managed care suggests that the rapid growth in the use of the procedures may be primarily a fee-for-service phenomenon. Of course, one would need longitudinal data to truly test the hypothesis.

While we focus on the fee-for-service versus managed care comparisons, some results for the remaining variables are worthy of brief discussion. Black women are less likely to receive an ultrasound during pregnancy than white women, but more likely at delivery. Black women are also more likely to receive a cesarean delivery. Non-medical risk factors such as smoking and drug use increase the likelihood of induction, but decrease the likelihood of cesarean deliveries. Older women are more likely to have cesarean deliveries, but less likely to receive an ultrasound during pregnancy, be induced, or have a fetal monitor.

\section{Women without medical risks or complications}

Table 3 reports utilization for people without medical risks or complications. Approximately 37 percent of all births are to women without any medical risks or complications. We would expect procedure utilization to be much lower for this group. Indeed, women without risks or complications are less likely to receive all four of the procedures being examined. The difference is particularly striking for cesarean deliveries as women with risks and complications are more than twice as likely to receive a cesarean section compared to those without risks or complications. A substantial difference in utilization also exists for induction/stimulation. 
Ultrasound is often standard in prenatal care and fetal monitors are common during delivery. As such the differential between the risks and no risks groups is much smaller for these procedures. Among insurance types, HMO Blue enrollees are least likely to have no risks or complications, while between 37 and 40 percent of enrollees in the other insurance types have no risks or complications.

$<$ Table 3>

The logit results are provided in Table 4. Managed care enrollees continue to be more likely to receive ultrasounds and HMO Blue enrollees are less likely to receive cesarean deliveries. Commercial HMO enrollees are no less likely to receive a cesarean delivery. HMO Blue enrollees are also more likely to receive induction/stimulation, while commercial HMO enrollees have greater utilization of fetal monitors.

The results for the remaining variables are quite similar to those discussed above. Once again, black women are less likely to receive an ultrasound during pregnancy than white women, but more likely at delivery. Black women without risks or complications are also less likely to receive a fetal monitor. Non-medical risk factors such as smoking and drug use increase the likelihood of all procedures. Older women are more likely to have cesarean deliveries, but less likely to receive an ultrasound during pregnancy, be induced, or have a fetal monitor.

$<$ Table 4>

While there are notable differences in procedure utilization between insurance types, we had also anticipated several differences between fee-for-service and managed care would depend on whether the pregnancy was high-risk. This does appear to be the case for BCBS enrollees. The results do suggest greater differences between BCBS and HMO Blue enrollees when there are no risks or complications. However, commercial fee-for-service and HMO differences in 
utilization are fairly small and do not vary substantially between the high-risk and low-risk pregnancies.

\section{Conclusion}

We extend prior research on the effect of managed care on the receipt of medical interventions. Two methods account for selection bias, the use of propensity scores and dividing the sample into two groups with relatively homogeneous medical needs (high-risk and low-risk pregnancies. Managed care enrollees are more likely to receive an ultrasound, which may be indicative of receiving better prenatal care. Managed care plans reduce the rate of cesarean deliveries, but such limitations may be beneficial given the substantial medical evidence that too many cesarean deliveries are performed.

The results for induction/stimulation of labor and fetal monitors differ for HMO Blue and commercial HMOs. However, given that most enrollees are in commercial plans, managed care reduces the rate of induction/stimulation and increases the rate of fetal monitor usage. The induction/stimulation findings are consistent with prior research and suggest that HMOs limit inductions/stimulations for elective reasons. Women with medical risks and complications of pregnancy are more likely to receive each procedure.

In addition, managed care coverage does not appear to have adverse consequences for utilization among women with medical risks and complications. Women with maternal risks are more likely to receive ultrasounds and commercial HMO enrollees are more likely to have fetal monitors. Overall, the results indicate that insurance coverage does influence treatment intensity, but that the utilization controls and provider financial incentives may not adversely affect care for pregnant women. 


\section{References}

Ahern, M., Rosenman, R., Hendryx, M.S., Siddharthan, K., and Silverstein, G. (1996). Predictors of HMO efficiency. Applied Economics, 28, 1381-1390.

Aitken, M.E., Warden, C.R., and Critchlow, C.W. (1997). The effect of health maintenance organization vs commercial insurance status on obstetrical management and outcome. Archives of Pediatrics and Adolescent Medicine, 151, 1104-1108.

Berger, M. and Messer, J. (2002). Public financing of health expenditures, insurance, and health outcomes. Applied Economics, 34, 2105-2113.

Blair, R.D., Ginsburg, P.B., and Vogel, R.J. (1975). Blue Cross-Blue Shield administrative costs: A study of non-profit health insurers. Economic Inquiry, 13, 237-251.

Carey, T.S., Weis, K., and Homer, C. (1991). Prepaid versus traditional Medicaid plans: Lack of effect on pregnancy outcomes and prenatal care. Health Services Research, 26, 166-181.

Chernew, M. (1995). HMO use of diagnostic tests: A review of the evidence. Medical Care Research and Review, 52, 196-222.

Currie, J., and Gruber, J. (2001). Public Health Insurance and Medical Treatment: The Equalizing Impact of the Medicaid Expansions. Journal of Public Economics, 82, 63-89.

Cutler, D., McClellan, M., and Newhouse, J.P. (2000). How does managed care do it? Rand Journal of Economics, 31, 526-548.

Decker, S.L. (2000). Medicaid, AFDC, and family formation. Applied Economics, 32, 19471956.

De Jaegher, K., and Jegers, M. (2000). A model of physician behavior with demand inducement. Journal of Health Economics, 19, 231-258.

Evans, R.G. (1974). Supplier-induced demand: Some empirical evidence and implications. In: Perlman, M. (Ed.), The Economics of Health and Medical Care. Macmillan: London, pp. 162201.

Farley, P.J. (1986). Theories of the price and quantity of physician services. Journal of Health Economics, 5, 315-333.

Flood, A.B., Fremont, A.M., Jin, K., Bott, D.M., Ding, J., Parker, Jr. R.C. (1998). How do HMOs achieve savings?: The effectiveness of one organization's strategies. Health Services Research, 33, 79-99.

Foreman, S.E., Wilson, J.A., Scheffler, R.M. (1996). Monopoly, monopsony and contestability in health insurance: A study of Blue Cross plans. Economic Inquiry, 34, 662-677. 
Foster, E.M. (2003). Propensity score matching: An illustrative analysis of dose-response. Medical Care, 41, 1183-1192.

Gruber, J. and McKnight, R. (2003). Why did employee health insurance contributions rise? Journal of Health Economics, 22, 1085-1104.

Gruber, J., and Owings, M. (1996). Physician financial incentives and cesarean section delivery. Rand Journal of Economics 27, 99-123.

Haggerty, L.A. (1999). Continuous electronic fetal monitoring: Contradictions between practice and research. Journal of Obstetric, Gynecologic, and Neonatal Nursing, 28, 409-416.

Hornbuckle, J., Vail, A., Abrams, K.R., and Thornton, J.G. (2000). Bayesian interpretation of trials: the example of intrapartum electronic fetal heart rate monitoring. British Journal of Obstetrical Gynaecology, 107, 3-10.

Huttin, C. (1997). Income distribution and consumer demand for health services. The case of prescribed medicines in the USA. Applied Economics, 29, 497-503.

Imbens, G.W. (2000). The role of the propensity score in estimating dose-response functions. Biometrika, 87, 706-710.

Keeler, E.B., and Brodie, M.A. (1993). Economic incentives in the choice between vaginal delivery and cesarean section. Milbank Quarterly, 71, 365-404.

Koroukian, S.M., Bush, D., and Rimm, A.A. (2001). Comparison of cesarean section rates in fee-for-service versus managed care patients in the Ohio Medicaid population, 1992-1997. American Journal of Managed Care, 7, 134-142.

Krieger, J.W., Connell, F.A., and Lo Gerfo, J.P. (1992). Medicaid prenatal care: A comparison if use and outcomes in fee-for-service and managed care. American Journal of Public Health, 82, 185-190.

Lindrooth, R.C., Norton, E.C., and Dickey, B. (2002). Provider selection, bargaining, and utilization management in managed care. Economic Inquiry, 40, 348-365.

Long, G., and Sprigg, A. (1998). A comparative study of routine versus selective fetal anomaly ultrasound screening. Journal of Medical Screening, 5, 6-10.

Manning, W.G., Leibowitz, A., Goldberg, G.A., Rogers, W.H., Newhouse, J.P. (1984). A controlled trial of the effect of a prepaid group practice on use of services. New England Journal of Medicine, 310, 1505-1510.

Mathews, T.J. (1997). Trends in stimulation and induction of labor, 1989-1995. Statistical Bulletin-Metropolitan Life Insurance Company, 78, 20-26. 
Miller, R. and Luft, H.S. (1994). Managed care plan performance since 1980. Journal of the American Medical Association, 271, 1512-1519.

Mossialos, E., Costa-Font, J., Davaki, K., and Karras, K. (2005). Is there 'patient selection' in the demand for private maternity care in Greece? Applied Economics Letters, 12, 7-12.

Oleske, D.M., Branca, M.L., Schmidt, J.B., Ferguson, R., and Linn, E.S. (1998). A comparison of capitated and fee-for-service Medicaid reimbursement methods on pregnancy outcomes. Health Services Research, 33, 55-73.

Quick, J.D., Greenlick, M.R., and Roghmann, K.J. (1981). Prenatal care and pregnancy outcome in an HMO and general population: A multivariate cohort analysis. American Journal of Public Health, 71, 381-390.

Rayburn, W.F., and Zhang, J. (2002). Rising rates of labor induction: present concerns and future strategies. Obstetrics and Gynecology, 100, 164-167.

Robinson, J.C., Gardner, L.B., and Luft, H.S. (1993). Health plan switching in anticipation of increased medical care utilization. Medical Care, 31, 43-51.

Roland, M., Feldman, R., and Wholey, D. (2004). Nash bargaining model of HMO premiums. Applied Economics, 36, 1329-1336.

Rosenbaum, P.R., and Rubin, D.B. (1983) The central role of the propensity score in observational studies for causal effects. Biometrika, 70, 41-55.

Schifrin, E., Jacobs, A.E., Romans, M., Cruess, D., and Kelly, R. (2001). Impact of managed care on obstetrician-gynecologists' practice: The providers' perspective. Women's Health Issues, $11,461-470$.

Seeds, J.W. (1996). The routine or screening obstetrical ultrasound examination. Clinical Obstetrics and Gynecology, 39, 814-830.

Stafford, R.S. (1990). Cesarean section use and source of payment: An analysis of California hospital discharge abstracts. American Journal of Public Health, 80, 313-315.

Sweha, A., Hacker, T.W., and Nuovo, J. (1999). Interpretation of the electronic fetal heart rate during labor. American Family Physician, 59, 2487-2500.

Thurston, N.K. (2002). Physician behavioral responses to variation in marginal income tax rates: Longitudinal evidence. Applied Economics, 34, 2093-2104.

Tussing, A.D., and Wojtowycz, M.A. (1994). Health maintenance organizations, independent practice associations, and cesarean section rates. Health Services Research, 29, 75-93. 
Weinstein, R.B., and Trussell, J. (1998). Declining cesarean delivery rates in California: An effect of managed care? American Journal of Obstetrics and Gynecology, 179, 657-664.

Wilner, S., Schoenbaum, S.C., Monson, R.R., and Winickoff, R.N. (1981). A comparison of the quality of maternity care between a health maintenance organization and fee-for-service practices. New England Journal of Medicine, 304, 784-787.

Wright, C.H., Gardin, T.H., and Wright, C.L. (1984). Obstetric care in a health maintenance organization and a private fee-for-service practice: A comparative analysis. American Journal of Obstetrics and Gynecology, 149, 848-856. 


\section{Notes}

${ }^{1}$ One exception is Currie and Gruber (2001), who examined the effect of Medicaid expansions during the early 1990s on utilization of the same four procedures.

2 Rosenbaum and Rubin (1983) proposed using propensity scores to adjust for pre-treatment differences when there are two treatment groups. Imbens (2000) extends the method to the multiple treatment case. Foster (2003) presents a nice illustration of using multiple treatment propensity scores in health services research.

3 There also exists international evidence that insurance affects the provision of cesarean deliveries. Mossialos, Costa-Font, Davaki, and Karras (2005) found that cesarean deliveries are 20 percent more likely when the woman has private health insurance.

${ }^{4}$ While not comparing managed care with fee-for-service insurances, Berger and Messer (2002) found that the share of national health expenditures from public sources was associated with increased mortality rates. Decker (2000) found that the introduction of the Medicaid program led to an increase in births to single women.

${ }^{5}$ Births occurring in another state or country, not occurring in a hospital, or which cannot be matched to the SPARCS data are eliminated. Also, data from New York City were not available since NYC maintains its own vital records department.

${ }^{6}$ Self-insured or self-pay patients are those patients for which there is no known insurance coverage. These could be either individuals who do not have coverage through their employer, who cannot afford coverage, affluent individuals who choose not to purchase insurance, or possibly individuals who have a benefactor who is taking the responsibility for the medical costs. Although the method of payment can be changed at a later date, these changes would not impact the provider's choice of procedure(s) at the time 
${ }^{7}$ Expectant mother's medical risk factors include anemia, mellitus diabetes, genetic diseases, genital herpes, heart disease, hemoglobinopathy, hepatitis b, chronic hypertension, previous low birth-weight infant, chronic lung disease, macrosomia or previous infant $>4000 \mathrm{~g}$, previous preterm infant, renal disease, RH sensitized, seizure disorders, previous spontaneous fetal death, thrombophlebitis, thyroid condition, gestational diabetes, in vitro fertilization, other fertilization treatment, hydramnios/oligohydramnios, pregnancy related hypertension, preeclampsia, eclampsia, incompetent cervix, acute lung disease, rubella, syphilis, other sexually transmitted disease, tuberculosis, uterine bleeding, viral disease, and other medical risk factor. Medical complications during labor or delivery are abruptio placenta, cephalopelvic disproportion, chorioamnionitis, coagulation defects, cord conditions, cord prolapse, failure to progress, fetal distress, fever, postpartum hemorrhage, cervical or vaginal lacerations, marginal sinus rupture, meconium particulate or moderate/heavy, non-vertex presentation, placenta previa, precipitous labor, prolonged rupture membrane ( $>12 \mathrm{hr}$.), premature rupture membrane ( $>1 \mathrm{hr} . \&<12 \mathrm{hr}$.), prolonged labor, retained placenta, seizures, uterine atony and other complications. Non-medical risk factors include smoking, alcohol use, drug use, mother's weight at delivery and weight gain during pregnancy.

8 Whereas we know the type of insurance coverage, the data do not indicate whether the insurance is a group or nongroup plan. Huttin (1997) found different patterns of prescription drug use enrollees in group and nongroup plans.

9 Insurance type is considered to be a choice variable for consumers, but Thurston (2002) finds that physician contracting with HMOs partially depends on geographic factors such as state tax rates. Thus, the extent of provider networks may differ across states, affecting the choices perceived by consumers.

10 The remaining procedures (ultrasound during delivery, fetal monitor, inducement/stimulation, and cesarean delivery) are not mutually exclusive. Nor is one procedure linked with the 
performance of another procedure. For example, an induced delivery may not be successful leading to a cesarean delivery. In other cases, only one of the procedures will be performed. As such, separate logit equations are estimated for each procedure treating each as an independent decision made by providers and patients.

${ }^{11}$ Ahern, Rosenman, Hendryx, Siddharthan, and Silerstein (1996) considered HMO efficiency in providing services, and how service provision depends on HMO ownership. The authors found that HMOs owned by physicians tend to use more physician services, but that hospital owned HMOs tend to use more inpatient services. Roland, Feldman, and Wholey (2004) examined commercial HMO premiums. Premiums are lower when there are more HMOs serving an area, especially among for-profit HMOs. Employer bargaining power is greater and premiums lower when the HMO has a higher ratio of administrative-to-total expenses.

${ }^{12}$ Some ultrasounds may also be performed during delivery, especially for certain complications and prior to some cesarean deliveries. In addition, an ultrasound may be performed for some post-term pregnancies. Over 96 percent of the ultrasounds reported in our data were performed prior to labor/delivery.

${ }^{13}$ It would be preferable to examine medically indicated and elective induction and stimulation separately, but the data do not contain the reason for receiving the procedure(s).

${ }^{14}$ See Hornbuckle, Vail, Abrams, and Thornton (2000) for a meta-analysis of the link between EFM usage and perinatal mortality.

${ }^{15}$ Computed as the difference in the marginal effects for fee-for-service and managed care BCBS plans. Marginal effects are computed as the difference in predicted probabilities between the relevant insurance category and those enrolled in commercial fee-for-service insurance with the remaining variables set to the sample means. 
Table 1

Procedure Utilization by Insurance Type

Patients with Complications and Risk Factors, 1993-1996

\begin{tabular}{|c|c|c|c|c|c|c|}
\hline \multirow[b]{2}{*}{ Procedure } & \multicolumn{2}{|c|}{ Blue Cross Blue Shield } & \multicolumn{2}{|c|}{ Commercial Insurance } & \multirow[b]{2}{*}{ Other } & \multirow[b]{2}{*}{ Total } \\
\hline & FFS & $\mathrm{HMO}$ & FFS & $\mathrm{HMO}$ & & \\
\hline Ultrasound during pregnancy & 0.937 & $0.974^{a}$ & 0.940 & 0.938 & 0.934 & 0.940 \\
\hline Ultrasound during delivery & 0.082 & $0.107^{\mathrm{a}}$ & 0.050 & $0.064^{a}$ & 0.071 & 0.070 \\
\hline Fetal monitor & 0.904 & $0.856^{a}$ & 0.925 & 0.925 & 0.935 & 0.919 \\
\hline Inducement & 0.531 & $0.629^{a}$ & 0.528 & $0.486^{a}$ & 0.528 & 0.528 \\
\hline Cesarean section & 0.368 & $0.303^{a}$ & 0.367 & $0.334^{a}$ & 0.291 & 0.328 \\
\hline Observations & 10,213 & 5,239 & 12,453 & 13,190 & 22,428 & 63,523 \\
\hline Proportion of insurance type & 0.169 & 0.371 & 0.168 & 0.195 & 0.220 & 0.200 \\
\hline Proportion of high-risk births & 0.161 & 0.082 & 0.196 & 0.208 & 0.353 & 1.000 \\
\hline
\end{tabular}

Data: 1993 -1996 NYS Vital Statistics (VS) matched infant birth-death file and the Statewide Planning and Research Cooperative System (SPARCS).

a - Denotes the fee-for-service and managed care utilization rates are significantly different at the 5 percent level of signficance. Significance is determined using pairwise t-tests. 
Table 2

The Effect of Insurance Coverage on Procedure Utilization

Patients with Medical Risks and Complications

New York State, 1993-1996

\begin{tabular}{|c|c|c|c|c|c|c|c|}
\hline \multirow[b]{3}{*}{ Procedure } & \multicolumn{4}{|c|}{ Blue Cross Blue Shield } & \multirow{2}{*}{\multicolumn{2}{|c|}{$\begin{array}{c}\text { Commercial } \\
\mathrm{HMO} \\
\end{array}$}} & \multirow{3}{*}{$\begin{array}{l}\text { Pseudo } \\
\text { r-square }\end{array}$} \\
\hline & \multicolumn{2}{|c|}{ FFS } & \multicolumn{2}{|c|}{ HMO Blue } & & & \\
\hline & coef. & marg eff & coef. & marg eff & coef. & marg eff & \\
\hline Ultrasound during pregnancy & $\begin{array}{r}0.0276 \\
(.021)\end{array}$ & 0.013 & $\begin{array}{r}4.778^{\star \star} \\
(.569)\end{array}$ & 0.233 & $\begin{array}{r}0.5714^{\star \star} \\
(.168)\end{array}$ & 0.028 & 0.0469 \\
\hline Ultrasound during delivery & $\begin{array}{r}1.253^{\star *} \\
(.201)\end{array}$ & 0.060 & $\begin{array}{r}.8837^{\star *} \\
(.221)\end{array}$ & 0.043 & $\begin{array}{r}-0.2153 \\
(.169)\end{array}$ & -0.010 & 0.1109 \\
\hline Fetal monitor & $\begin{array}{r}-0.5825^{\star \star} \\
(.186)\end{array}$ & -0.034 & $\begin{array}{r}-1.131^{\star \star} \\
(.198)\end{array}$ & -0.066 & $\begin{array}{r}0.6478^{\star \star} \\
(.149)\end{array}$ & 0.038 & 0.0795 \\
\hline Induction/stimulation & $\begin{array}{r}-0.0010 \\
(.107)\end{array}$ & 0.000 & $\begin{array}{r}0.8638^{\star \star} \\
(.155)\end{array}$ & 0.215 & $\begin{array}{r}-0.7234^{\star \star} \\
(.085)\end{array}$ & -0.180 & 0.0959 \\
\hline Cesarean section & $\begin{array}{r}-0.0618 \\
(.150)\end{array}$ & -0.009 & $\begin{array}{r}-1.107^{\star *} \\
(.218)\end{array}$ & -0.164 & $\begin{array}{r}-0.1704 \\
(.121)\end{array}$ & -0.025 & 0.4643 \\
\hline
\end{tabular}

Notes: Data are from the 1993-1996 New York State Vital Statistics data and Statewide Planning and Research Cooperative System. Separate logistic regressions are estimated for each procedure. The specifications also include the woman's age, race, education, medical risks, complications of pregnancy, non-medical risks, other insurance types (Medicaid fee-for-service, Medicaid managed care, Medicare, CHAMPUS, self-pay), the trimester in which prenatal care began, whether a breech birth, the length of gestation, the mother's weight and weight gain, the babies weight, and the degree of urbanization.

Commercial fee-for-service insurance is the omitted insurance category. All regressions are weighted by the propensity score (the inverse of the predicted probability of choosing the insurance type actually selected).

Marginal effects are computed as the difference in predicted probabilities between the relevant insurance category and those enrolled in commercial fee-for-service insurance with the remaining variables set to the sample means.

** denotes significance at the 5 percent level; * 10 percent level. 
Table 3

Procedure Utilization by Insurance Type

Patients without Complications or Risk Factors, 1993-1996

\begin{tabular}{|c|c|c|c|c|c|c|}
\hline \multirow[b]{2}{*}{ Procedure } & \multicolumn{2}{|c|}{ Blue Cross Blue Shield } & \multicolumn{2}{|c|}{ Commercial Insurance } & \multirow[b]{2}{*}{ Other } & \multirow[b]{2}{*}{ Total } \\
\hline & FFS & $\mathrm{HMO}$ & FFS & $\mathrm{HMO}$ & & \\
\hline Ultrasound during pregnancy & 0.871 & $0.886^{a}$ & 0.871 & $0.877^{a}$ & 0.869 & 0.872 \\
\hline Ultrasound during delivery & 0.044 & $0.013^{a}$ & 0.021 & $0.027^{\mathrm{a}}$ & 0.021 & 0.027 \\
\hline Fetal monitor & 0.825 & 0.836 & 0.828 & $0.851^{\mathrm{a}}$ & 0.867 & 0.844 \\
\hline Inducement & 0.323 & $0.428^{a}$ & 0.340 & $0.332^{a}$ & 0.316 & 0.330 \\
\hline Cesarean section & 0.138 & $0.106^{a}$ & 0.137 & 0.140 & 0.098 & 0.125 \\
\hline Observations & 25,294 & 2,915 & 31,546 & 25,765 & 37,471 & 122,991 \\
\hline Proportion of insurance type & 0.404 & 0.203 & 0.407 & 0.371 & 0.356 & 0.374 \\
\hline Proportion of low-risk births & 0.206 & 0.024 & 0.256 & 0.209 & 0.305 & 1.000 \\
\hline
\end{tabular}

Data: 1993 -1996 NYS Vital Statistics (VS) matched infant birth-death file and the Statewide Planning and Research Cooperative System (SPARCS).

a - Denotes the fee-for-service and managed care utilization rates are significantly different at the 5 percent level of signficance. Significance is determined using pairwise t-tests. 
Table 4

The Effect of Insurance Coverage on Procedure Utilization

Patients without Medical Risks or Complications New York State, 1993-1996

\begin{tabular}{|c|c|c|c|c|c|c|c|}
\hline \multirow[b]{3}{*}{ Procedure } & \multicolumn{4}{|c|}{ Blue Cross Blue Shield } & \multirow{2}{*}{\multicolumn{2}{|c|}{$\begin{array}{c}\text { Commercial } \\
\mathrm{HMO}\end{array}$}} & \multirow{3}{*}{$\begin{array}{l}\text { Pseudo } \\
\text { r-square }\end{array}$} \\
\hline & \multicolumn{2}{|c|}{ Blue Cross } & \multicolumn{2}{|c|}{ HMO Blue } & & & \\
\hline & coef. & marg eff & coef. & marg eff & coef. & marg eff & \\
\hline Ultrasound during pregnancy & $\begin{array}{r}-0.0606 \\
(.091)\end{array}$ & -0.007 & $\begin{array}{l}1.755 \\
(1.20)\end{array}$ & 0.189 & $\begin{array}{r}.2021^{\star \star} \\
(.093)\end{array}$ & 0.022 & 0.0180 \\
\hline Ultrasound during delivery & $\begin{array}{r}2.906^{\star *} \\
(.176)\end{array}$ & 0.062 & $\begin{array}{r}-12.82^{\star \star} \\
(3.46)\end{array}$ & -0.275 & $\begin{array}{r}1.034^{* *} \\
(.198)\end{array}$ & 0.022 & 0.0436 \\
\hline Fetal monitor & $\begin{array}{r}-0.0965 \\
(.081)\end{array}$ & -0.012 & $\begin{array}{r}2.040^{\star *} \\
(.933)\end{array}$ & 0.259 & $\begin{array}{r}0.5575^{\star \star} \\
(.085)\end{array}$ & 0.071 & 0.0208 \\
\hline Induction/stimulation & $\begin{array}{r}-0.1369 * \star \\
(.065)\end{array}$ & -0.030 & $\begin{array}{r}5.859^{\star *} \\
(.716)\end{array}$ & 1.283 & $\begin{array}{r}-0.017 \\
(.066)\end{array}$ & -0.004 & 0.0217 \\
\hline Cesarean section & $\begin{array}{r}-0.6210 \\
(.089)\end{array}$ & -0.006 & $\begin{array}{r}-4.917^{\star \star} \\
(1.20)\end{array}$ & -0.461 & $\begin{array}{r}0.1151 \\
(.091)\end{array}$ & 0.011 & 0.0830 \\
\hline
\end{tabular}

Notes: Data are from the 1993-1996 New York State Vital Statistics data and Statewide Planning and Research Cooperative System. Separate logistic regressions are estimated for each procedure. The specifications also include the woman's age, race, education, non-medical risks, other insurance types (Medicaid fee-for-service, Medicaid managed care, Medicare, CHAMPUS, self-pay), the trimester in which prenatal care began, whether a breech birth, the length of gestation, the mother's weight and weight gain, the babies weight, and the degree of urbanization.

Commercial fee-for-service insurance is the omitted insurance category. All regressions are weighted by the propensity score (the inverse of the predicted probability of choosing the insurance type actually selected).

Marginal effects are computed as the difference in predicted probabilities between the relevant insurance category and those enrolled in commercial fee-for-service insurance with the remaining variables set to the sample means.

** denotes significance at the 5 percent level; * 10 percent level. 